American Journal of Environmental Sciences 5 (3): 364-370, 2009

ISSN 1553-345X

(C) 2009 Science Publications

\title{
Bioaccumulation of Arsenic by Fungi
}

\author{
Ademola O. Adeyemi \\ Division of Environmental and Applied Biology, College of Life Sciences, \\ University of Dundee, Dundee, DD1 4HN, Scotland, UK
}

\begin{abstract}
Problem statement: Arsenic is a known toxic element and its presence and toxicity in nature is a worldwide environmental problem. The use of microorganisms in bioremediation is a potential method to reduce as concentration in contaminated areas. Approach: In order to explore the possible bioremediation of this element, three filamentous fungi-Aspergillus niger, Serpula himantioides and Trametes versicolor were investigated for their potential abilities to accumulate (and possibly solubilize) arsenic from an agar environment consisting of non buffered mineral salts media amended with $0.2,0.4,0.6$ and $0.8 \%(\mathrm{w} / \mathrm{v})$ arsenopyrite (FeAsS). Growth rates, dry weights, arsenic accumulation and oxalate production by the fungi as well as the $\mathrm{pH}$ of the growth media were all assessed during this study. Results: There was no visible solubilization of FeAsS particles underneath any of the growing fungal colonies or elsewhere in the respective agar plates. No specific patterns of growth changes were observed from the growth ratios of the fungi on agar amended with different amounts of FeAsS although growth of all fungi was stimulated by the incorporation of varying amounts of FeAsS into the agar with the exception of A. niger on $0.4 \%(\mathrm{w} / \mathrm{v})$ amended agar and T. versicolor on $0.8 \%(\mathrm{w} / \mathrm{v})$ amended agar. The amounts of dry weights obtained for all three fungi also did not follow any specific patterns with different amounts of FeAsS and the quantities obtained were in the order A. niger $>S$. himantioides $>T$. versicolor. All fungi accumulated as in their biomasses with all amounts of FeAsS although to varying levels and T. versicolor was the most effective with all amounts of FeAsS while A. niger was the least effective. Conclusion: The accumulation of arsenic in the biomasses of the test fungi as shown in this study may suggested a role for fungi through their bioaccumulating capabilities as agents in the possible bioremediation of arsenic contaminated environments.
\end{abstract}

Key words: Bioaccumulation, arsenic, Aspergillus niger, Serpula himantioides, Trametes versicolor

\section{INTRODUCTION}

Arsenic is a metalloid that is widely distributed in the earth's crust and is present at an average concentration of $2 \mathrm{mg} \mathrm{kg}^{-1[1]}$. It is generally regarded as a toxic element and its toxicity to living organisms has long been acknowledged. For instance, in historical times in rural Germany, it was used as a means to dispose of the old owner of a house, farm or land thereby speeding up the inheritance process ${ }^{[2]}$. More recently, there has been an increased awareness of its risk to plants, animals and human health ${ }^{[3-8]}$.

In the environment, arsenic is present in more than 200 mineral species, the most common of which is arsenopyrite (FeAsS), an arsenic sulfide. Inorganic arsenic of geological origin is found in groundwater used for drinking purposes in several parts of the world such as Bangladesh and West Bengal, India ${ }^{[1,6]}$. Chronic exposure to high levels of arsenic and its compounds, especially in drinking water can have several carcinogenic, mutagenic and teratogenic implications ${ }^{[1,7,9]}$.

According to estimates, about a third of the atmospheric flux of arsenic is of natural origin, volcanic action being the most important natural source, followed by low-temperature volatilization ${ }^{[1]}$. Common anthropogenic sources such as mining, metal smelting and the use of arsenic containing agricultural chemicals, as well as the weathering of arsenic-containing rocks, e.g., arsenopyrite, lead to the contamination of air, water and soil ${ }^{[4,9-12]}$. Of total world arsenic production, it has been estimated that about $70 \%$ is used in timber treatment as copper chrome arsenate, $22 \%$ in agricultural chemicals and the remainder in glass, pharmaceuticals and non-ferrous alloys ${ }^{[1]}$.

In nature, the responses of microorganisms to toxic metal (loid)s can dramatically alter metal(loid) abundances and elemental speciation, leading to a range 
of transformations such as mobilization, immobilization and mineral neogenesis ${ }^{[13]}$. In the course of these transformations, fungi in particular may be able to accumulate these metal(loid)s into their cells. The intracellular uptake of metal ions from a substrate into living cells, otherwise known as bioaccumulation may lead to the biological removal of metals by fungi ${ }^{[14]}$. Such accumulation of heavy metals by fungal biomass may be particularly relevant because of its potential low cost application in bioremediation and recovery of metals. Furthermore, as fungi play fundamental roles in the natural environment especially regarding decomposition, transformation and nutrient cycling, a knowledge of their responses in high metal concentration states may be particularly relevant, in this case, to the detoxification of arsenic polluted habitats. Prompted by the combined abilities of fungi to render metals soluble from insoluble compounds and accumulate them from the dissolved state, this study sought to evaluate the accumulation and possible solubilization of arsenopyrite at different concentrations in solid media by free-living filamentous fungi.

\section{MATERIALS AND METHODS}

Organisms, media and culture conditions: The following fungi-Aspergillus niger (ATCC No. 201373), Serpula himantioides (from Dr N. White, University of Abertay Dundee, UK) and Trametes versicolor (from Prof. C. Evans, University of Westminster, UK) were used for the experiment. They were maintained on the same medium used for the experiment, a non-buffered mineral salts medium comprising ( $\mathrm{g} \mathrm{L}^{-1}$ distilled water) $\left(\mathrm{NH}_{4}\right)_{2} \mathrm{SO}_{4}, \quad 5 ; \quad \mathrm{KH}_{2} \mathrm{PO}_{4}, \quad 0.5 ; \quad \mathrm{MgSO}_{4} .7 \mathrm{H}_{2} \mathrm{O}, \quad 0.2$; $\mathrm{CaCl}_{2} \cdot 6 \mathrm{H}_{2} \mathrm{O}, 0.05 ; \mathrm{NaCl}, 0.1 ; \mathrm{FeCl}_{3} \cdot 6 \mathrm{H}_{2} \mathrm{O}, 0.0025$; traces $\left(\mathrm{ZnSO}_{4} .7 \mathrm{H}_{2} \mathrm{O}, 0.004 ; \mathrm{MnSO}_{4} .4 \mathrm{H}_{2} \mathrm{O}, 0.004\right.$; $\left.\mathrm{CuSO}_{4} .5 \mathrm{H}_{2} \mathrm{O}, 0.004\right)$ and D-glucose, 20. Stock concentrations of the mineral salt solutions were autoclaved separately at $121^{\circ} \mathrm{C}$ for $15 \mathrm{~min}$ before use. The experimental fungi were incubated at $25^{\circ} \mathrm{C}$ in the dark for 3 days prior to the start of the experiment.

Mineral preparation and experimental set up: Ground (i.e., powdered) arsenopyrite with particle sizes between 38-106 $\mu \mathrm{m}$ were obtained from R.G. Widdowson (Scarborough, UK) and used for the experiment. Amounts of arsenopyrite which would give $0.2,0.4,0.6$ and $0.8 \%(\mathrm{w} / \mathrm{v})$ in the final agar plates were weighed out into aluminium foil packets and oven sterilized at $70^{\circ} \mathrm{C}$ for at least $24 \mathrm{~h}$. The agar was prepared using $15 \mathrm{~g} \mathrm{~L}^{-1}$ Lab M Agar No. 1 (IDG, Lancashire, UK) and autoclaved at $121^{\circ} \mathrm{C}$ for $15 \mathrm{~min}$. After cooling (to about $55^{\circ} \mathrm{C}$ ) in a water bath, indicated quantities of individually autoclaved salts listed above from stock solutions were added to the molten agar. One pre-weight foil packet of each amount was added to the agar preparation and mixed well to ensure a homogenous distribution of the mineral particles. About $20 \mathrm{~mL}$ per plate of agar was poured into $90 \mathrm{~mm}$ diameter Petri dishes with or without the addition of arsenopyrite. After solidification of the agar, sterile dialysis membranes prepared by boiling twice for 10 min in $\mathrm{ddH}_{2} \mathrm{O}$ and rinsed thoroughly on each occasion prior to autoclaving at $121^{\circ} \mathrm{C}$ for 15 min were placed under aseptic conditions onto the surface of the agar in each Petri dish. The dialysis membrane allowed passage of nutrients and/or metabolites between the agar and the fungi and provided a convenient means of removing the mycelia from the agar.

All the plates (FeAsS-containing and FeAsS-free) were inoculated with $7 \mathrm{~mm}$ diameter discs of A. niger, $S$. himantioides and $T$. versicolor cut from the margin of a three day old grown mycelia on the mineral salts medium described above. The inoculated plates were incubated at $25^{\circ} \mathrm{C}$ over an eight-day period. Daily measurements of the growth radius of the hyphae and that of any clear zones under or around the colonies were taken either until the mycelia reached the edge of the Petri dish or the experimental period was over. Petri dishes were also examined under a light microscope for any transformations such as formation of clear zones, indicative of mineral dissolution and crystal formation in the agar. Growth rates were then calculated from this data. After eight days, colonies were harvested into aluminium foil cups by peeling the biomass from the dialysis membranes. These were oven-dried at $70^{\circ} \mathrm{C}$ until reaching a constant weight. The dry weights of the mycelia were then measured on a Mettler-Toledo PR203 weighing balance.

In order to obtain a $\mathrm{pH}$ profile of the agar surface under fungal colonies, $\mathrm{pH}$ measurements were made across the Petri dish at $20 \mathrm{~mm}$ intervals at the end of the experiment using an Orion model 720A pH meter.

All statistical analyses were carried out using Minitab for Windows 12.1 (Minitab Inc., USA). Correlation analysis was completed using the Pearson correlation method.

Arsenic content determination: For arsenic content analysis of the biomasses, $2 \mathrm{~mL}$ concentrated $\mathrm{HNO}_{3}$ was added to each biomass sample in a fume hood and incubated for at least $6 \mathrm{~h}$ after which they were transferred to a heating block at $90^{\circ} \mathrm{C}$ for $20 \mathrm{~h}$. Arsenic was then determined using the methods described in Agrawal et al. ${ }^{[9]}$. Briefly, $1 \mathrm{mg} \mathrm{mL}^{-1}$ arsenic stock solution was prepared by dissolving $173.34 \mathrm{mg}$ of 
sodium arsenite in $100 \mathrm{ml} \mathrm{ddH_{2 }} 0$. To a $1 \mathrm{~mL}$ aliquot of nitric acid-digested biomass, $0.4 \mathrm{~mL}$ of $1 \%$ potassium iodate was added followed by the addition of $0.2 \mathrm{~mL}$ of $0.5 \mathrm{M} \mathrm{HCl}$. The reaction mixture was gently shaken upon the addition of $0.2 \mathrm{~mL}$ leucocrystal violet solution and 1-2 drops of $2 \mathrm{M} \mathrm{NaOH}$ solution. Leucocrystal violet solution was prepared by adding $25 \mathrm{mg}$ of

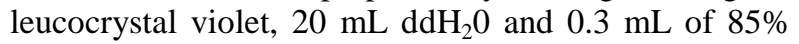
(v/v) phosphoric acid into a $250 \mathrm{~mL}$ Erlenmeyer flask, gently shaking until the dye dissolved and then diluted to give a final volume of $100 \mathrm{~mL}$. Each aliquot of the nitric acid-digested biomass reaction mixture was kept in a heating block at $40^{\circ} \mathrm{C}$ for $5 \mathrm{~min}$. The solution was diluted to $5 \mathrm{~mL}$ with $\mathrm{ddH}_{2} \mathrm{O}$ and the absorbance was measured at $592 \mathrm{~nm}$ using a VERSAmax ${ }^{\mathrm{TM}}$ turnable microplate reader spectrophotometer with SOFTmax ${ }^{\circledR}$ PRO software (Molecular Devices, California, USA).

Oxalate determination in agar: In order to determine the amounts of oxalate formed in the agar, agar from each plate (mineral-containing and mineral-free) was mashed and put into $250 \mathrm{~mL}$ Erlenmeyer conical flasks. $40 \mathrm{~mL}$ of $1 \mathrm{M} \mathrm{HCl}$ was added to each flask and the flasks were shaken overnight in a rotating incubator at $120 \mathrm{rpm}$. A $1 \mathrm{~mL}$ aliquot of the resulting liquid solution for each sample was collected in an eppendorf tube, to which cation exchange resin (Bio-Rad AG 50W-X4; BioRad Laboratories, Richmond, CA, USA) was added. The oxalate content of the samples was then determined enzymatically according to the methods described in the Sigma diagnostics oxalate kit (Procedure no. $591)^{[15]}$. In summary, Sigma sample diluents and oxalate reagents $\mathrm{A}$ and $\mathrm{B}$ were reconstituted according to the reagent preparation instructions contained in the kit. A known volume of sample diluent was added to an equal volume of agar sample for analysis. The $\mathrm{pH}$ was measured intermittently and adjusted using either $1 \mathrm{M}$ $\mathrm{HCl}$ or $1 \mathrm{M} \mathrm{KOH}$ until the $\mathrm{pH}$ was between 5 and 7 . $1 \mathrm{~mL}$ of oxalate reagent $\mathrm{A}$ was added to each sample after which $0.1 \mathrm{~mL}$ of oxalate reagent B was added. Upon addition, each sample was mixed by gentle inversion and incubated at room temperature (between $18-37^{\circ} \mathrm{C}$ ) for $5 \mathrm{~min}$. Standards were prepared in the following concentrations $0 \mathrm{mM}$ (blank), $0.125 \mathrm{mM}$, $0.25 \mathrm{mM}, 0.5 \mathrm{mM}$ and $1 \mathrm{mM}$. Absorbances of standards and samples derived from the agar were measured at $590 \mathrm{~nm}$ using a VERSAmax ${ }^{\mathrm{TM}}$ turnable microplate reader spectrophotometer with SOFTmax ${ }^{\circledR}$ PRO software (Molecular Devices, California, USA).

\section{RESULTS}

Growth rates: The growth rates of the fungi grown on agar containing different amounts of arsenopyrite are shown in Table 1 and are expressed in terms of ratios. The growth ratio is the colony growth rate in the presence of the mineral compound $\left(\mathrm{R}_{\mathrm{m}}\right)$ relative to the colony control growth rate $\left(\mathrm{R}_{\mathrm{c}}\right)^{[16]}$. There was no visible solubilization of FeAsS particles underneath any of the growing fungal colonies or elsewhere in the respective agar plates. As a result, solubilization rates could not be obtained nor ratios calculated. A growth ratio greater than 1.0 indicates that growth of the fungus was stimulated by the addition of the metal compound. On the other hand, a growth ratio less than 1.0 indicates growth inhibition. No specific patterns of growth changes with different amounts of FeAsS were observed from the ratios. The incorporation of $0.2 \%$ $(w / v)$ FeAsS into the agar medium stimulated the growth of $A$. niger as the growth ratio was greater than 1.0. When $0.4 \%$ (w/v) FeAsS was present, the growth ratio was 0.95 indicating growth inhibition with this amount. Growth at higher amounts of 0.6 and $0.8 \%$ $(w / v)$ was stimulated with ratios of 1.05 and 1.07 respectively. The growth of $S$. himantioides was stimulated in the agar medium with all amounts of FeAsS since the derived growth ratios were all higher than 1.0. With T. viride, growth was stimulated with all amounts except when $0.8 \%(\mathrm{w} / \mathrm{v})$ was present in the agar medium. The ratio when this amount was present in the agar was 0.95 , thus indicating inhibition.

Dry weights of fungal biomass and pH of agar: The dry weight values recorded for $A$. niger, $S$. himantioides and $T$. versicolor are shown in Fig. 1. Increasing amounts of FeAsS had differing influences on the biomasses of all three fungi. With A. niger, the highest amount of biomass was obtained when $0.2 \%$ (w/v) FeAsS was present in the agar. There were subsequent decreases in biomasses with increasing FeAsS amounts from $0.4-0.8 \%(\mathrm{w} / \mathrm{v})$. Dry weights of $S$. himantioides were increased by the presence of FeAsS in the growth medium with all amounts although it followed no specific pattern. Biomass was highest in the $0.6 \%$ (w/v) FeAsS-amended medium, followed by $0.8 \%$, then 0.2 and $0.4 \%(w / v)$ FeAsS-amended media.

Table 1: Growth ratios of Aspergillus niger, Serpula himantioides and Trametes versicolor on non-buffered mineral salts medium amended with different amounts of FeAsS after 8 d growth

Amount of FeAsS (w/v)

\begin{tabular}{lllll} 
& & & \\
Organism & $0.2 \%$ & $0.4 \%$ & $0.6 \%$ & $0.8 \%$ \\
\hline Aspergillus niger & 1.07 & 0.95 & 1.05 & 1.07 \\
Serpula himantioides & 1.27 & 1.15 & 1.19 & 1.29 \\
Trametes versicolor & 1.40 & 1.15 & 1.46 & 0.95 \\
\hline
\end{tabular}

Control growth rates (mean values \pm standard error of mean; three replicates each) for A. niger $=3.81 \pm 0.39 \mathrm{~mm} \mathrm{day}^{-1}, S$. himantioides $=3.44 \pm 0.62 \mathrm{~mm}$ day $^{-1}$ and $T$. versicolor $=2.12 \pm 0.42 \mathrm{~mm}^{\text {day }}{ }^{-1}$ 
Am. J. Environ. Sci., 5 (3): 364-370, 2009

Table 2: $\mathrm{pH}$ values \pm standard error of the mean measured underneath growing colonies of Aspergillus niger, Serpula himantioides and Trametes versicolor on non-buffered mineral salts medium amended with different amounts of $\mathrm{FeAsS}$ after $8 \mathrm{~d}$ and incubated at $25^{\circ} \mathrm{C}$. The figures shown are average values of three replicates

\begin{tabular}{|c|c|c|c|c|c|}
\hline \multirow[b]{2}{*}{ Organism } & \multirow{2}{*}{$\begin{array}{c}\text { Biotic } \\
\text { Control }^{\S}\end{array}$} & \multicolumn{4}{|c|}{ Amount of FeAsS (w/v) } \\
\hline & & $0.2 \%$ & $0.4 \%$ & $0.6 \%$ & $0.8 \%$ \\
\hline Aspergillus niger & $2.01 \pm 0.00$ & $2.07 \pm 0.00$ & $2.11 \pm 0.00$ & $2.17 \pm 0.00$ & $2.22 \pm 0.00$ \\
\hline Serpula himantioides & $3.00 \pm 0.01$ & $3.02 \pm 0.01$ & $3.13 \pm 0.01$ & $3.33 \pm 0.02$ & $3.41 \pm 0.05$ \\
\hline Trametes versicolor & $2.96 \pm 0.00$ & $2.98 \pm 0.00$ & $3.51 \pm 0.03$ & $3.79 \pm 0.03$ & $4.13 \pm 0.07$ \\
\hline Abiotic control $^{*}$ & $4.68 \pm 0.03$ & $5.42 \pm 0.04$ & $5.76 \pm 0.03$ & $5.83 \pm 0.03$ & $5.94 \pm 0.01$ \\
\hline \multicolumn{6}{|c|}{$\begin{array}{l}\text { §: The values under the biotic control column represent the } \mathrm{pH} \text { underneath growing colonies of A. niger, S. himantioides and } T . \text { versicolor on } \\
\text { FeAsS-free agar (i.e., } 0 \% \mathrm{FeAsS} \text { ) with the exception of the abiotic control. *: The values in the abiotic control row represent the } \mathrm{pH} \text { of agar with } \\
\text { the addition of the respective amounts of FeAsS, without fungal growth (i.e., agar only) }\end{array}$} \\
\hline \multicolumn{6}{|c|}{$\begin{array}{l}\text { Table 3: Amounts of As in nmol } \mathrm{mg}^{-1} \text { dry weight } \pm \text { standard error of the mean accumulated in biomasses of Aspergillus niger, Serpula } \\
\text { himantioides and Trametes versicolor on non-buffered mineral salts medium amended with different amounts of FeAsS after } 8 \text { day and } \\
\text { incubated at } 25^{\circ} \mathrm{C} \text {. The figures shown are average values of three replicates }\end{array}$} \\
\hline & \multicolumn{5}{|c|}{ Amount of FeAsS (w/v) } \\
\hline Organism & $0.2 \%$ & & & $0.6 \%$ & $0.8 \%$ \\
\hline Aspergillus niger & $13.73 \pm 4.53$ & & & $41.40 \pm 18.60$ & $27.30 \pm 2.96$ \\
\hline Serpula himantioides & $74.00 \pm 18.50$ & & & $62.23 \pm 6.60$ & $112.80 \pm 14.50$ \\
\hline Trametes versicolor & $208.50 \pm 13.50$ & & & $195.00 \pm 12.40$ & $229.00 \pm 10.30$ \\
\hline
\end{tabular}

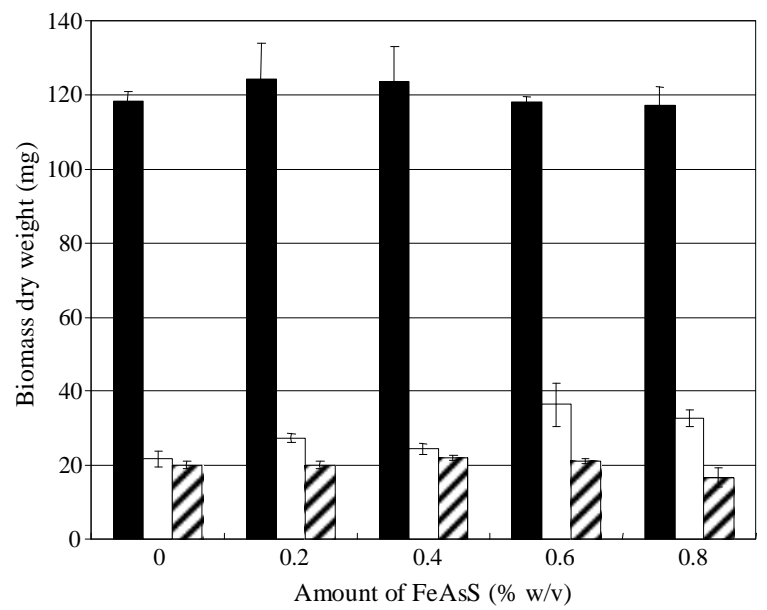

Fig. 1: Dry weights of Aspergillus niger (๘), Serpula himantioides ( $\square)$ and Trametes versiolor $(\square)$ grown on FeAsS-free agar medium and agar amended with $0.2,0.4,0.6$ and $0.8 \%$ (w/v) FeAsS oven-dried at $70^{\circ} \mathrm{C}$ to constant weight after $8 \mathrm{~d}$ growth. The figures used for the graph were average values of three replicates. Bars indicate the Standard Errors of the Mean (SEM)

The incorporation of $0.2 \%(\mathrm{w} / \mathrm{v})$ FeAsS into the agar media had no effect on the biomass of $T$. versicolor when compared with the control and the highest amount of biomass was obtained with growth on $0.4 \%$ (w/v) FeAsS-amended media. There were decreases in biomasses of this fungus with increasing FeAsS amounts. Statistical descriptions for amounts of biomass produced by the fungi thus show negative correlations between the amounts of FeAsS in the agar media and dry weights for $A$. niger and T. versicolor $(\mathrm{r}=-0.412$ and-0.447 respectively). There was however, a positive correlation in the case of $S$. himantioides $(\mathrm{r}=0.817)$.

The values presented in Table 2 show a gradual increase in the $\mathrm{pH}$ of the experimental medium (without any fungal growth, i.e., abiotic control) from $4.68 \pm 0.03$ (mean value \pm standard error of mean; three replicates each) in the FeAsS-free medium to $5.94 \pm 0.01$ with $0.8 \%(w / v)$ FeAsS-amended medium. Fungal growth on FeAsS-free media (control) revealed $A$. niger was the most acidic with a $\mathrm{pH}$ of 2.01 , followed by $T$. versicolor with a $\mathrm{pH}$ of 2.96 , then $S$. himantioides with a $\mathrm{pH}$ of $3.00 \pm 0.01$. Also, all three fungi reduced the $\mathrm{pH}$ of varying amounts of FeAsS-amended media and in all cases, there was reduced acidity with higher amounts. In other words, as the amounts of FeAsS in the media increased, $\mathrm{pH}$ as a result of fungal growth also increased with all three fungi and this is indicated in the positive correlation between both variables $(\mathrm{r}=0.997$, 0.987 and 0.990 , for A. niger, S. himantioides and T. versicolor respectively).

Arsenic accumulation: The data presented in Table 3 shows the amounts of arsenic (As) accumulated in the biomasses of Aspergillus niger, Serpula himantioides and Trametes versicolor. The values are expressed in nmol mg ${ }^{-1}$ dry weight and they show that $T$. versicolor had the highest levels of As accumulation per mg dry weight of biomass with all amounts of FeAsS in the agar. 
Am. J. Environ. Sci., 5 (3): 364-370, 2009

Table 4: Amounts of oxalate in $\mathrm{mM} \pm$ standard error of the mean produced by Aspergillus niger, Serpula himantioides and Trametes versicolor grown on agar containing varying amounts of FeAsS after 8 day and incubated at $25^{\circ} \mathrm{C}$. The figures shown are average values of three replicates

\begin{tabular}{lccccc}
\hline & & \multicolumn{3}{c}{ Amount of FeAsS (w/v) } \\
Organism & Control & $0.2 \%$ & $0.4 \%$ & $0.6 \%$ & $0.8 \%$ \\
\hline Aspergillus niger & $0.056 \pm 0.003$ & $0.070 \pm 0.003$ & $0.055 \pm 0.006$ & $0.052 \pm 0.009$ & $0.041 \pm 0.001$ \\
Serpula himantioides & $0.279 \pm 0.031$ & $0.153 \pm 0.025$ & $0.204 \pm 0.011$ & $0.306 \pm 0.052$ & $0.188 \pm 0.025$ \\
Trametes versicolor & $0.063 \pm 0.029$ & $0.103 \pm 0.019$ & $0.031 \pm 0.009$ & $0.051 \pm 0.022$ & $0.041 \pm 0.007$ \\
\hline
\end{tabular}

Generally, accumulation of As in the fungal biomasses was in the order $T$. versicolor $>S$. himantioides > A. niger. Upon statistical analysis, there was a positive correlation between the amounts of FeAsS in the media and the amounts of As accumulated by A. niger and $S$. himantioides ( $\mathrm{r}=0.107$ and 0.324 respectively) while there was a negative correlation with $T$. versicolor $(r=-0.091)$.

Oxalate production: The amounts of oxalate produced by the fungi as shown in Table 4 indicate with $A$. niger, the incorporation of $0.2 \%(\mathrm{w} / \mathrm{v}) \mathrm{FeAsS}$ into the agar increased oxalate production from $0.056 \pm 0.003 \mathrm{mM}$ (mean values \pm standard error of mean; three replicates each) to $0.070 \pm 0.003 \mathrm{mM}$ followed by a decrease with increasing FeAsS amounts. A similar pattern was followed by $T$. versicolor as there was an increase from $0.063 \pm 0.029 \mathrm{mM}$ in the control to $0.103 \pm 0.019 \mathrm{mM}$ when $0.2 \%(\mathrm{w} / \mathrm{v})$ FeAsS was present in the medium. No specific pattern was detected with $S$. himantioides although the presence of $0.6 \%$ (w/v) FeAsS led to an increase in oxalate production to $0.306 \pm 0.052 \mathrm{mM}$ when compared to the control where $0.279 \pm 0.031 \mathrm{mM}$ oxalate was produced. The amounts of oxalate produced by $S$. himantioides were greater than those of either $A$. niger or $T$. versicolor with all amounts of FeAsS. When subjected to statistical analysis, these results showed negative correlations between the amounts of FeAsS in the media and oxalate production by $A$. niger, $S$. himantioides and $T$. versicolor ( $\mathrm{r}=-0.731,-0.071$ and -0.544 respectively).

\section{DISCUSSION}

The three fungi tested in this study accumulated arsenic from arsenopyrite in their biomasses to varying degrees. $T$. versicolor was the most efficient in accumulation with all amounts, accumulating up to 15 times the amounts accumulated by $A$. niger which was the least effective in accumulation. In environments or media laden with high toxic-metal concentrations, the general expectation is usually a reduced microbial growth response as a result of the toxicity exerted by the pollutants on microbial cells.
This study has demonstrated this may not always be the case. The increased growth which resulted when FeAsS was present in the media at most amounts, relative to the control indicate these fungi show some resistance to As toxicity although the precise mechanism(s) by which toxic effects are overcome remain unclear. A plausible explanation for this is the possible utilization of $\mathrm{Fe}$ present in FeAsS for fungal growth. One mechanism however, by which fungi may be able to survive in and tolerate high toxic metal-containing environments is through the formation of oxalates which results from the oxalic acid they secrete ${ }^{[17]}$. Despite the negative correlation of increasing amounts of arsenopyrite to oxalate production in all three fungi shown by statistical analysis $(\mathrm{r}=-0.731$ for A. niger, -0.071 for $S$. himantioides and-0.544 for T. versicolor), there was an increase in growth by the fungi when compared to the control in the majority of cases. With the exception of growth by A. niger on $0.4 \%$ (w/v) and T. versicolor on $0.8 \%(\mathrm{w} / \mathrm{v}) \mathrm{FeAsS}$ amended media, fungal growth was enhanced with the addition of arsenopyrite to the media. Biomasses produced by the fungi with the varying amounts of FeAsS were either equal to or greater than that produced by the control in each case except for T. versicolor grown on $0.8 \%$ (w/v) FeAsS amended medium.

Oxalate, organic acid production and acidification through proton exudation by fungi may result in the solubilization of insoluble metal-bearing minerals by fungal species. Often times especially with organic acids, this is usually evident through crystal formation in the solubilized zones, underneath growing colonies and elsewhere in the agar. In contrast to previous studies in which such solubilization was demonstrated $^{[18-22]}$, no visible solubilization of arsenopyrite by these fungi occurred throughout the duration of this study. Also, upon examination under a light microscope, no crystals (usually indicative of cation immobilization as oxalates) were observed underneath growing colonies of the fungi or elsewhere in the agar plates with all amounts of FeAsS. Thus, there was no biological immobilization of arsenic in this study and although possible arsenic immobilization as crystals has implications for disposal and 
bioavailability, it has only been demonstrated by physico-chemical processes ${ }^{[7,23-25]}$ and there is yet to be any evidence that microorganisms can play a role in achieving this.

Environmental factors such as $\mathrm{pH}$ influence the abundance of different arsenic forms in natural environments $^{[26]}$. For instance, a decrease in $\mathrm{pH}$ is known to increase heavy metal availability ${ }^{[27]}$. In this study, the addition of increasing amounts of FeAsS to the experimental agar generally increased the $\mathrm{pH}$ of the media in all cases. However, fungal growth with the varying FeAsS amounts reduced the $\mathrm{pH}$ of the media when compared with the abiotic controls (i.e., agar with the addition of the respective amounts of FeAsS, without fungal growth). With all three fungi, acidity generally reduced with higher amounts of FeAsS and the order of acidification of growth media by the fungi was $A$. niger $>S$. himantioides $>T$. versicolor. In addition, the differences in the $\mathrm{pH}$ of the agar with the different amounts by all three fungi were statistically significant $(\mathrm{p}<0.05)$. Fungal acidification of media could have arisen through organic acid secretion during growth, proton extrusion via the proton translocating ATPase, absorption of nutrients in exchange for protons or carbonic acid formation through respiratory $\mathrm{CO}_{2}$ production $^{[28]}$.

\section{CONCLUSION}

In summary, while the immobilization of arsenic as a result of fungal interaction with arsenopyrite did not occur in this study, the accumulation of arsenic in the biomasses of the test fungi may suggest a role for fungi through their bioaccumulating capabilities as agents in the possible bioremediation of arsenic contaminated environments.

\section{ACKNOWLEDGEMENT}

The researcher is indebted to Geoffrey Gadd for provision of fungal cultures, laboratory space and access to facilities used for this study.

\section{REFERENCES}

1. World Health Organization, 2001. Arsenic and Arsenic Compounds. 2nd Edn., (IPCS Environmental Health Criteria Series No. 224). World Health Organization, Geneva. http://www.inchem.org/documents/ehc/ehc/ehc224. htm

2. Nies, D.H., 1999. Microbial heavy-metal resistance. Applied Microbiol. Biotechnol., 51: 730-750. DOI: 10.1007/s002530051457
3. Harrington, J.M., S.E. Fendorf and R.F. Rosenzweig, 1998. Biotic generation of arsenic (III) in metal (loid)-contaminated freshwater lake sediments. Environ. Sci. Technol., 32: 2425-2430. DOI: 10.1021/es971129k

4. Lin, Z. and R.W. Puls, 2000. Adsorption, desorption and oxidation of arsenic affected by clay minerals and aging process. Environ. Geol., 39: 753-759. DOI: 10.1007/s002540050490

5. Suhendrayatna, A. Ohki and S. Maeda, 2001. Biotransformation of arsenite in freshwater foodchain models. Applied Organometal. Chem., 15: 277-284. DOI: 10.1002/aoc.139

6. Ramaswami, A., S. Tawachsupa and M. Isleyen, 2001. Batch-mixed iron treatment of high arsenic waters. Water Res., 35: 4474-4479. DOI: 10.1016/ S0043-1354(01)00168-3

7. Riveros, P.A., J.E. Dutrizac and P. Spencer, 2001. Arsenic disposal practices in the metallurgical industry. Can. Metallurg. Quart., 40: 395-420.

8. Kapaj, S., H. Peterson, K. Liber and P. Bhattacharya, 2006. Human health effects from chronic arsenic poisoning-a review. J. Environ. Sci. Health Part A., 41: 2399-2428. DOI: $10.1080 / 10934$ 520600873571

9. Agrawal, O., G. Sunita and V.K. Gupta, 1999. A sensitive colorimetric method for the determination of arsenic in environmental and biological samples. J. Chinese Chem. Soc., 46: 641-645. http://www. ceps.com.tw/ec/ecjnlissuelist.aspx ?jnlcattype $=1 \&$ jn lptype $=4 \&$ jnltype $=27 \&$ newIssueIID $=62759 \&$ jnliid $=3598$

10. Hiroki, M., 1993. Effect of arsenic pollution on soil microbial population. Soil Sci. Plant Nutr., 39: 227-235.

http://ci.nii.ac.jp/cinii/servlet/QuotDisp?LOCALID $=$ ART0001861143\&DB=NELS\&USELANG $=$ en

11. Taboada-de La Calzada, A., M.C. Villa-Lojo, E. Beceiro-Gonzalez, E. Alonso-Rodriguez and Prada-Rodriguez, 1998. Determination of arsenic species in environmental samples: Use of the alga Chlorella vulgaris for arsenic (III) retention. Trends Anal. Chem., 17: 167-175. DOI: 10.1016/S01659936(98)00002-8

12. Mohan, D. and C.U. Pittman, 2007. Arsenic removal from water/wastewater using adsorbents-a critical review. J. Hazard. Mat., 142: 1-53. DOI: 10.1016/j.jhazmat.2007.01.006

13. Gadd, G.M., 1993. Interactions of fungi with toxic metals. New Phytol., 124: 25-60. DOI: 10.1111/j. 1469-8137.1993.tb03796.x 
14. Singh, H., 2006. Mycoremediation: Fungal bioremediation. Wiley-Interscience, Hoboken, N.J., pp 484-532.

15. Sigma Diagnostics Inc., 1999. Oxalate Procedure no. 591. Sigma-Aldrich Co., Poole, UK.

16. Sayer, J.A., 1996. The transformation of insoluble metal compounds by fungi. Unpublished $\mathrm{PhD}$ Thesis, University of Dundee, Dundee, UK.

17. Jarosz-Wilkolazka, A. and G.M. Gadd, 2003. Oxalate production by wood-rotting fungi growing in toxic metal-amended medium. Chemosphere, 52: 541-547. DOI: 10.1016/S0045-6535(03)00235-2

18. Sayer, J.A., S.L. Raggett and G.M. Gadd, 1995. Solubilization of insoluble metal compounds by soil fungi: Development of a screening method for solubilizing ability and metal tolerance. Mycol. Res., 99: 987-993. DOI: 10.1016/S09537562(09)80762-4

19. Sayer, J.A., M. Kierans and G.M. Gadd, 1997. Solubilisation of some naturally occurring metalbearing minerals, limescale and lead phosphate by Aspergillus niger. FEMS. Microbiol. Lett., 154: 29-35. DOI:10.1111/j.15746968.1997.tb12620.x

20. Sayer, J.A. and G.M Gadd, 1997. Solubilization and transformation of insoluble inorganic metal compounds to insoluble metal oxalates by Aspergillus niger. Mycol. Res., 101: 653-661. DOI: $10.1017 / \mathrm{S} 0953756296003140$

21. Gharieb, M.M., J.A. Sayer and G.M. Gadd, 1998. Solubilization of natural gypsum $\left(\mathrm{CaSO}_{4} \cdot 2 \mathrm{H}_{2} \mathrm{O}\right)$ and the formation of calcium oxalate by Aspergillus niger and Serpula himantiodes. Mycol. Res., 102 : 825-830. DOI: $10.1017 /$ S0953756297005510
22. Gharieb, M.M., 2000. Nutritional effects on oxalic acid production and solubilization of gypsum by Aspergillus niger. Mycol. Res., 104: 550-556. DOI: 10.1017/S0953756299001707

23. Filippou, D. and G.P. Demopoulos, 1997. Arsenic immobilization by controlled scorodite precipitation. J. Miner. Metals Mater. Soc., 49: 52-55. DOI: $10.1007 / \mathrm{s} 11837-997-0034-3$

24. Bothe, J.V. and P.W. Brown, 1999. Arsenic immobilization by calcium arsenate formation. Environm. Sci. Technol., 33: 3806-3811. DOI: 10.1021/es980998m

25. Mambote, R.C.M., M.A. Reuter, A. van Sandwijk and P. Krijgsman, 2001. Immobilization of arsenic in crystalline form using aqueous solution by hydrothermal processing above $483.15 \mathrm{~K}$. Minerals Eng., 14: 391-403. DOI: 10.1016/S08926875(01)00019-X

26. Woolson, E.A., 1977. Generation of alkylarsines from soil. Weed Sci. 25: 412-416.

27. Gadd, G.M. and A.J. Griffiths, 1978. Microorganisms and heavy metal toxicity. Microbiol. Ecol., 4: 303-317. DOI: 10.1007/BF020 13274

28. Burgstaller, W. and F. Schinner, 1993. Leaching of metals with fungi. J. Biotechnol., 27: 91-116. DOI: 10.1016/0168-1656(93)90101-R 